\title{
Comparative Analysis of Vaginal Bacterial Diversity in Northern-Chinese Women Associated With or Without Bacterial Vaginosis
}

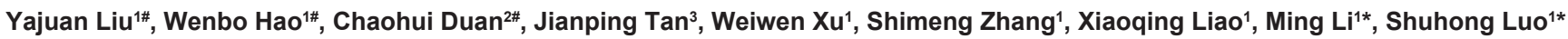

'Institute of Antibody Engineering, School of Biotechnology, Southern Medical University, 1838 N. Guangzhou Avenue, Guangzhou People's Republic of China 'Laboratory of Clinical Immunology, the Sun Yat-Sen Memorial hospital, Sun Yat-Sen University, Guangzhou People's Republic of China

${ }^{3}$ Department of obstetrics and gynecology, the Sun Yat-Sen Memorial hospital, Sun Yat-Sen University, Guangzhou People's Republic of China

\#These authors contributed equally to this work.

\begin{abstract}
Background: Bacterial Vaginosis (BV) is the common vaginal infection in women and it has been linked to enhanced risks for pre-term birth, pelvic inflammatory disease and sexually transmitted diseases. BV is caused by a disorder of vaginal microbiota which changes from the normal lactobacillus dominated community to a more diverse community of non-lactobacillus bacteria. Several previous reports analyzed the overall vaginal microbial communities of volunteers from limited sampling area and they suggested a possible link between the vaginal microbial contents and the ethnicity of women. Here, we analyzed the diversity of vaginal microbiota in 10 subjects associated with $\mathrm{BV}(\mathrm{BV}+)$ and 10 subjects without $\mathrm{BV}(\mathrm{BV}-)$ from the metropolitan area of Herbing in Northern China using full-length $16 \mathrm{~S}$ rDNA.

Results: The vaginal bacterial communities detected in subjects with $\mathrm{BV}$ were much more taxon rich and diverse than those without BV. At a $97 \%$ sequence similarity cutoff, the number of operational taxonomic units (OTUs) per 10 subjects with $B V$ was nearly three times greater than 10 subjects without BV by $29.4 \pm 9.3$ versus $11.7 \pm 7.8$ (Mean \pm $\mathrm{SD})$. Our data confirmed that there is a shift in the abundance of bacterial species present in the vaginal environment when BV and non-BV groups were compared. Each sequence read was assigned to a genus or a species when possible. Principal component analysis was performed at genus levels. Most BV+ samples clustered together while there were two clusters among BV- samples. Several bacteria have been found to be associated with BV, including Gardnerella, Atopobium, Peptoniphilus, Leptotrichia/Sneathia, Prevotella, Parvimonas and Dialister, Based on result of classification, four possible novel phylotype microorganisms were found.
\end{abstract}

Conclusions: The data presented here on the composition and richness of the vaginal microbial ecosystem in $\mathrm{BV}$ and health state will provide the depth insight in the etiology of BV.

Keywords: Bacterial vaginosis; $16 \mathrm{~S}$ rDNA amplification; Clone library; Vaginal flora; Microbiology

Abbreviations: BV: Bacterial vaginosis; OTUs: Operational taxonomic units; PCA: Principal component analysis

\section{Background}

Bacterial vaginosis $(\mathrm{BV})$ is the common vaginal infection in women of reproductive age, and is the most common etiology of vaginal symptoms which prompt women to seek medical care [1]. Numerous health problems including preterm labor resulting in low birth weight [1], pelvic inflammatory disease [2], and acquisition of HIV [3] are closely related to $\mathrm{BV}$.

$\mathrm{BV}$ is caused by an imbalance of naturally occurring bacterial flora in healthy vagina with the common normal bacterial flora of Lactobacillus crispatus and Lactobacillus iners. Lactobacilli include some hydrogen peroxide-producing species that help to prevent other vaginal microorganisms from excessive growth. Previous reports showed that BV patients have dromatic changes in vaginal from the normal lactobacillus dominating community to the diversity of nonlactobacillus bacteria [4]. Alone the absence of Lactobacillus does not define an unhealthy state. Complementarily, the presence of solely, or a combination of, Atopobium, Gardnerella, Peptostreptococcus, Prevotella, Pseudomonas, and/or Streptococcus (often noxious bacteria when in/on humans) does not define an unhealthy state [5]. In the past, the composition and diversity of human vagina microbiota were detected by cultural methods which had many limitations for the really circumstance. The advent of PCR based techniques and pyrosequencing made it possible to further examine this complex microbial niche. The small ribosomal subunit or $16 \mathrm{~S}$ rDNA gene was often used as the most common target for molecular identification of bacteria. Bacterial $16 \mathrm{~S}$ rDNA gene is present in all bacteria and has conservative regions that can be targeted with broad range PCR primers [6]. Areas of amplified sequences can be used to characterize and identify the bacteria origin, in order to determine their phylogenetic relationships.

In this study, we used the full-length $16 \mathrm{~S}$ rDNA to determine the diversity of vaginal microbiota in $10 \mathrm{BV}+$ and $10 \mathrm{BV}$ - women from Haerbin in Northern China and to get the basic data for the bacterial imbalance when BV occured. Our results revealed that analysis of vaginal microbiota and the clustering of microbial profile could help in the identification of bacterial vaginosis and assessment of women's vaginal health.

*Corresponding author: Dr. Shuhong Luo, Institute of Antibody Engineering School of Biotechnology, Southern Medical University, Guangzhou Avenue, Guangzhou, Guangdong Province, China; Tel: 8620-61648325 ; Fax : 862061648554; E-mail: shluo815@yahoo.com

Received March 17, 2012; Accepted May 22, 2012; Published May 30, 2012

Citation: Liu Y, Hao W, Duan C, Tan J, Xu W, et al. (2012) Comparative Analysis of Vaginal Bacterial Diversity in Northern-Chinese Women Associated With or Without Bacterial Vaginosis. J Medical Microbiol Diagnosis S5:001. doi:10.4172/21610703.S5-001

Copyright: (c) 2012 Liu Y, et al. This is an open-access article distributed under the terms of the Creative Commons Attribution License, which permits unrestricted use, distribution, and reproduction in any medium, provided the original author and source are credited. 


\section{Methods}

\section{Human subjects}

This study was approved by both the ethics committee of Southern Medical University and by the Heilongiiang Provincial People's Hospital. Twenty women were recruited for this study. All the women enrolled provided informed consent and none of them declined participation. The study was supervised by experts from Southern Medical University and Heilongjiang Provincial People's Hospital. These subjects were at various (recorded) times of their menstrual cycle with 19-55 years of age, including $10 \mathrm{BV}$ positive $(\mathrm{BV}+)$ women $(\mathrm{BV}+$ group, aged $36.8 \pm 15.02$.) and $10 \mathrm{BV}$ negative (BV-) women (BVgroup, aged $29.1 \pm 4.43$ ), who came to the Department of Obstetrics and Gynecology, Heilongjiang Provincial People's Hospital, for routine gynecology examination from August 2009 to July 2011.

BV status was assessed based on Amsel criteria for all subjects [7]. The participants who met three or more of the following criteria were clinically diagnosed as $\mathrm{BV}+$ : homogeneous vaginal discharge, $>20 \%$ clue cells on wet mount microscopy, elevated $\mathrm{pH}(\geq 4.5)$ of vaginal fluid, and release of a fishy amine odor on addition of $10 \%$ potassium hydroxide solution to vaginal fluid ("whiff" test). Diagnosis was confirmed using BV Quick-Test sialidase test kit (Zhuhai Livzon Pharmaceutical Group Inc, China, Cat. No.2401325). Participants without these symptoms were defined as BV negative group (BV-).

Participants were excluded by any of the following exclusion criteria : $<18$ years of age, pregnancy, taking contraceptive steroids, complaints of urogenital symptoms or noticeable infection on physical examination of the urogenital tract, diabetes mellitus, the use of antibiotics or vaginal antimicrobials in the previous month, presence of an intrauterine device, vaginal intercourse within the latest 3 days, known active infection due to Chlamydia, yeast, Trichomonas vaginalis, clinically apparent herpes simplex infection, or defined diagnosed HPV, HSV-2, or HIV-1 infection. The clinical data of each participant were summarized in Table 1.

\section{Sample collection and preparation}

The sample swabs were collected as described by Kin et al. [8]. Two swabs were taken from each woman. One was used for sialidase test, vaginal smears, and saline microscopy, the other was used for bacterial genomic DNA extraction. This vaginal swab was placed in sterile cryovial with $1 \mathrm{ml}$ normal saline, packaged in ice packs and transferred to the laboratory immediately in ice-box, and stored at $-80^{\circ} \mathrm{C}$ for future test.

\section{Extraction of genomic DNA}

The bacterial cells retrieved on swabs were vigorously agitated to dislodge cells. The cells were pelleted by centrifugation at 10,000 $\mathrm{g}$ for $10 \mathrm{~min}$. Then bacterial genomic DNA was extracted using QIAamp DNeasy Blood and Tissue Kit (QIAGEN, Hilden, Germany; Cat. No. 69504) followed the manufacturer's instructions. Briefly, the bacterial pellet was suspended in $200 \mu \mathrm{l}$ of normal saline, and then added 20 $\mu \mathrm{l}$ of proteinase $\mathrm{K}$ solution and $200 \mu \mathrm{l}$ of lysis buffer (Buffer $\mathrm{AL}$ ). Vertex the mixtures for homogenization and incubated at $56^{\circ} \mathrm{C}$ for 30 min. Then, $200 \mu \mathrm{l}$ of $100 \%$ ethanol was added and mixed thoroughly, the mixture was then pipeted into the QIAamp spin column and centrifuged at 8,000 $\mathrm{g}$ for $1 \mathrm{~min}$. The QIAamp spin column was placed in a new $2 \mathrm{ml}$ collection micro-tube, and the containing filtrate was discarded. The spin columns were washed with $500 \mu \mathrm{l}$ buffer AW1 and AW2 provided in the kit. Finally, the genomic DNA was eluted

\begin{tabular}{|c|c|c|c|c|c|c|}
\hline $\begin{array}{l}\text { Sample } \\
\text { No }\end{array}$ & Age & $\begin{array}{l}\text { BV } \\
\text { Test }^{a}\end{array}$ & Clue cell & $\begin{array}{l}\text { rod-shaped } \\
\text { bacteria }\end{array}$ & $\begin{array}{l}\text { WBC } \\
\text { Count }^{\mathrm{b}}\end{array}$ & $\begin{array}{l}\text { Clinical } \\
\text { Diagnosis }^{c}\end{array}$ \\
\hline \multicolumn{7}{|c|}{ BV+ Group } \\
\hline 124 & 30 & + & + & ++ & W++ & BV \\
\hline 127 & 27 & + & + & + & W+++ & BV \\
\hline 130 & 55 & + & - & ++ & W++++ & BV \\
\hline 131 & 19 & + & + & ++ & W++ & BV \\
\hline 133 & 30 & + & + & ++ & W++++ & BV \\
\hline 227 & 57 & + & + & ++ & W+++ & BV \\
\hline 228 & 58 & + & + & ++ & W++ & BV \\
\hline 232 & 29 & + & + & + & W+++ & BV \\
\hline 245 & 21 & + & + & ++ & W++++ & BV \\
\hline 251 & 42 & + & + & + & W++ & BV \\
\hline \multicolumn{7}{|c|}{ BV- Group } \\
\hline 113 & 29 & - & - & Miscellaneous+ & W+ & PE \\
\hline 125 & 21 & - & - & Miscellaneous + + & W++ & PE \\
\hline 136 & 28 & - & - & Miscellaneous+ & W++ & PE \\
\hline 138 & 30 & - & - & Miscellaneous+ & W++ & PE \\
\hline 146 & 32 & - & - & Miscellaneous+ & W++ & PE \\
\hline 223 & 22 & - & - & Miscellaneous+ & W++ & PE \\
\hline 229 & 32 & - & - & Miscellaneous+ & W++ & PE \\
\hline 235 & 31 & - & - & Miscellaneous+ & W++ & PE \\
\hline 237 & 35 & - & - & Miscellaneous+ & W+ & PE \\
\hline 249 & 31 & - & - & & W+ & PE \\
\hline
\end{tabular}

aBV test is based on a sialidase test kit.

${ }^{\mathrm{b}} \mathrm{W}$ values are the white blood cell counts per viewing field under microscope. $\mathrm{W}+$ indicates a value greater than 10 and $\mathrm{W}++, \mathrm{W}+++, \mathrm{W}++++$ greater than 20,30 and 40 respectively.

'Diagnosis was based on physician's comments. PE indicates that the sample was collected during a routine physical examination.

Table 1: Patient information of volunteer subjects.

with $100 \mu \mathrm{l}$ of elution buffer (Buffer AE). The concentration of DNA was determined by NanoDrop ND-1000 spectrophotometer (Thermo Electron Corporation, USA). The integrity and size of the extracted DNA were estimated and checked by $1.0 \%$ agarose gel electrophoresis containing $0.5 \mathrm{mg} / \mathrm{ml}$ ethidium bromide. All the DNA samples were stored at $-20^{\circ} \mathrm{C}$ until use.

\section{PCR amplification}

Highly conserved sequences of the Escherichia coli $16 \mathrm{~S}$ rDNA was used to design the primers for PCR amplication. The forward primer was 8f: 5'-AGAGTTTGAT CMTGGCTCAG-3', M = A + C. In the European Ribosomal RNA Database, $8 \mathrm{f}$ is called BSF8/20 (www.psb.ugent.be/rRNA). The reverse primer was 1492r: 5'-TACG GYTACCTTGTTACGACTT-3', Y $=\mathrm{C}+\mathrm{T}[9,10]$. The anticipated amplification product from the of microbial genomic DNA templates was nearly complete $16 \mathrm{~S}$ rDNA (>1.4 kb) [11]. PCR amplification was performed with Promega (GoTaq, Madison WI) PCR kit and followed the manufacturer's instructions. Total $50 \mu \mathrm{l}$ PCR mixture contained 0.1 $\mu \mathrm{M}$ of each primer, $25 \mu \mathrm{l}$ of Promega master mix, $3 \mu \mathrm{l}$ of DNA extract and distilled water. The amplify procedure included $95^{\circ} \mathrm{C}$ for $3 \mathrm{~min}$, amplified for 30 cycles where each cycle consisted of $95^{\circ} \mathrm{C}, 1 \mathrm{~min} ; 52$ ${ }^{\circ} \mathrm{C}, 1 \mathrm{~min}$; and $72^{\circ} \mathrm{C}, 2 \mathrm{~min} 30 \mathrm{sec}$, followed by $72^{\circ} \mathrm{C}, 10 \mathrm{~min}$. The 1.4 $\mathrm{kb}$ amplicons were purified used the gel extraction kit (Omega Cat. D2500).

\section{$16 \mathrm{~S}$ rDNA gene cloning library construction and sequencing}

16S rDNA PCR products were cloned into the pMD19T (Takara, Dalian) vector and transferred to $E$. coli TOP 10 competent cells (TianGen) according to the manufacturer's recommendations. The TOP 10 cells were plated onto Luria-Bertani agar plates containing 
$100 \mu \mathrm{g} / \mathrm{ml}$ ampicillin and $20 \mu \mathrm{g} / \mathrm{ml} \mathrm{X-gal} \mathrm{and} \mathrm{incubated} \mathrm{overnight} \mathrm{at}$ $37^{\circ} \mathrm{C}$. Approximately 200 white, well-isolated colonies were randomly selected from each of library. Single colonies were picked from the agar plates and transferred with sterile tips to the wells of a 96 well plate filled with LB Broth supplemented with $200 \mu \mathrm{g}$ ampicillin $/ \mathrm{ml}$ and incubated at $37^{\circ} \mathrm{C}$ for $3 \mathrm{~h}$. For each sample, at least one 96-well plate containing a library with $>90 \%$ of the colonies carrying cloned inserts was sequenced by using Applied Biosystems BigDye-terminator chemistry and the Applied Biosystems 3730 DNA Analyzer (Carlsbad, CA) with universal primer M13 reverse -48 .

\section{Sequence processing and data analysis}

The clone sequences were edited and processed by soft package. Raw sequence data were base-calling by PHRED and assigns a quality score as Q20 to each base edited and processed to accurate reads for alignment $[12,13]$. In all cases, vector and primer sequences were removed and quality trimmed from the clone sequences by using the LUCY program [14,15]. 37 clones of sequences are shorter than 200 bps or empty vector without insert sequence, thus were cut off. The related bacterial $16 \mathrm{~S}$ rDNA sequences in the RDP II database (http:// rdp.cme.msu.edu/) with high Seqmatch scores $(>0.9)$, were selected and used to assign by RDP naïve Bayesian rRNA Classifier for further analysis $[15,16]$. Analysis of the 8 clone sequences, which did not match, revealed that nearly all of them were probably not unique or unknown phylotypes. Based on the Seqmatch results, the clone sequences could be assigned to the type strains in the RDP II.

\section{Statistical analysis}

Bray-Curtis distance analysis was used to determine the differences in microbial population profiles. The Bray-Curtis dissimilarity index $[17,18]$, which is equivalent to a doubly weighted form of the SørensenDice dissimilarity index, was calculated according to the equation when $\sum_{i x i j}=1$ and $\sum_{i x i k}=1$, where $d_{j k}$ is the dissimilarity or distance between communities $j$ and $k$, and $x_{i j}$ and $x_{i k}$ are the fractional or percentage populations of component i found in communities $j$ and $k$. This distance was used to calculate the distance matrix for cluster analysis using the unweighted-pair group method using average linkages in the PHYLIP package. Phylotype diversity of the combined vaginal libraries within each subject was estimated by Simpson's reciprocal and ShannonWiener's diversity indices, using the EstimateS software (http://viceroy. eeb.uconn.edu/estimates). The OTU, rarefaction, Chaol and ACE estimation were analyzed using the mothur [19] (v.1.6.0, http://www. mothur.org/wiki/Main-Page). The statistical significance of differences in microbial community composition, and Shannon and Simpson index between sample categories was determined by SPSS with chitest and t-test. For bootstrap values, three methods (Fitch, parsimony, and maximum likelihood) with 100 re-samplings were performed using FITCH, DNAPARS, DNAMLK, SEQBOOT, and CONSENSE in PHYLIP.

\section{Results}

\section{Sequence analysis}

Clones were sequenced with a single read using M13 rev-48 primer and showed that nearly complete $16 \mathrm{~S}$ rDNA PCR product was cloned into pMD19T vector. Total of 3245 sequences passed quality control and were used for data analysis; 1893 sequences for BV+ group and 1346 sequences for BV- group. Sequences were classified based on self-similarities rather than matches to an external database and were grouped into operational taxonomic units (OTUs) with cutoffs of each sequence similarity using the MOTHUR package (http://www.mothur.
org/wiki/Main-Page) [19]. As described previously [20], rarefaction curves were generated for unique, $1 \%, 2 \%, 3 \%$, sequence dissimilarities. For phylogenetic analyses, the core data set of representative sequences with $97 \% 16 \mathrm{~S}$ rDNA sequence similarity to definite the phylogenetic species. As shown in Figure 1, the rarefaction curve in BV-group almost reached the saturation level. However, there was much more richness in bacterial diversity in BV+ individuals than in BV-individuals at the $97 \%$ similarity level. The number of OTUs continued to increase at the $97 \%$ or $98 \%$ similarity level in BV+ group (Figure 1), which indicated that additional sampling was needed to determine the true microbial diversity in BV+ vaginal community.

The taxonomic assignments of vaginal bacterial community members and the associated diversity estimation for each subject are shown in Table 2. The sequences identified in these groups covered the majority of the clone libraries presented in our detected samples for the Good's coverage weremore than $98.0 \%$ for all sequences in the two groups according to the estimated species diversity indices. Furthermore, as estimated by Chaol and ACE diversity indices, the number of OTUs detected was close to the total number of OTUs for the two groups of vaginal communities analyzed at the $3 \%$ dissimilarity level. Based on the number of sequences or OTUs and relative proportions, Chaol and ACE richness estimators were measured for the number of microbial species in the samples. This also proved that our clone libraries were well-covered during sequencing. Taxon definitions of $99 \%, 98 \%$, and $97 \%$ OTUs were assigned using the Mothur package. The numbers of OTU taxa per subjects with BV of Mean \pm SD were $39.8 \pm 11.9,31.2 \pm 11.1,29.4 \pm 9.3$ versus $16.2 \pm 11.6$, $11.3 \pm 8.5,11.7 \pm 7.8$ correspond to the subjects without BV at $99 \%$, 98\%, 97\% similarity respectively. The OUT taxa detected per subject were dramatically higher $(\mathrm{P} \leq 0.001)$ in subjects with $\mathrm{BV}$ than in subjects without BV for all phylotype definitions (Figure 2). Similarly,

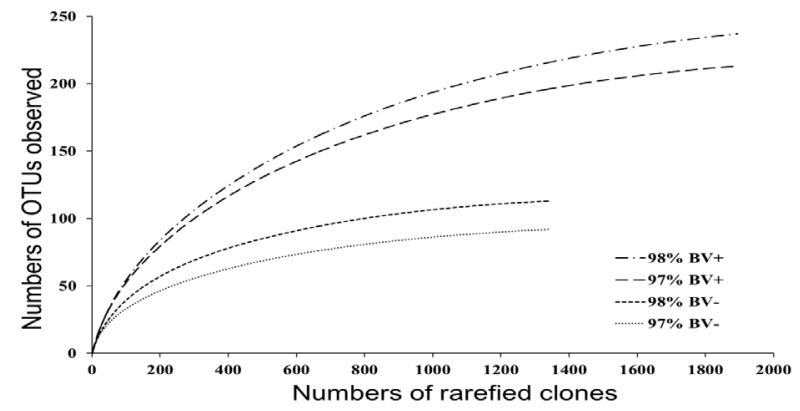

Figure 1: Rarefaction curves for BV+ and BV- groups used to estimate richness at a $97 \%$ or $98 \%$ similarity level.

\begin{tabular}{|l|l|l|l|l|l|l|l|l|}
\hline Group & Reads & OTUs $^{1}$ & Good $^{2}$ & ACE & Chao & Shannon $^{3}$ & Evenness & Simpson \\
\hline BV+ & 1893 & 213 & 0.981 & 230 & 222 & 4.469 & 0.592 & 0.02544 \\
\hline BV- & 1346 & 92 & 0.989 & 99 & 96 & 3.401 & 0.472 & 0.068199 \\
\hline
\end{tabular}

${ }^{1}$ The operational taxonomic units (OTUs) were defined with $3 \%$ dissimilarity level. ${ }^{2}$ The coverage percentage (Good), richness estimators (ACE and Chao1) and diversity indices (Shannon and Simpson) were calculated using Good's method. (Good, 1953) and the MOTHUR program.

${ }^{3}$ The Shannon index of evenness was calculated with the formula $E=H / \ln (S)$ where $\mathrm{H}$ is the Shannon diversity index and $\mathrm{S}$ is the total number of sequences in that group.

Table 2: Comparison of phylotype coverage and diversity estimation of the $16 \mathrm{~S}$ rRNA gene libraries at the $3 \%$ dissimilarity. 
Citation: Liu Y, Hao W, Duan C, Tan J, Xu W, et al. (2012) Comparative Analysis of Vaginal Bacterial Diversity in Northern-Chinese Women Associated With or Without Bacterial Vaginosis. J Medical Microbiol Diagnosis S5:001. doi:10.4172/2161-0703.S5-001

Page 4 of 9

diversity was higher $(\mathrm{P}<0.005)$ in subjects with $\mathrm{BV}$ than that without BV. The Shannon diversity index in subjects with BV was $2.79 \pm 0.5$, and in subjects without BV was $1.56 \pm 0.9$ based on the $97 \%$ similarity taxonomic definition.

The Shannon and Simpson indices [21], for both clone libraries were far from the critical values, Shannon Index (3.401 in BV- group Vs. 4.469 in BV+ group) and Simpson Index (0.068199 in BV-group Vs.0.02544 in BV+ group). The diversity of both groups was abundant; however the diversity was higher in subjects with BV, which the Shannon diversity index was 1.3 times greater than subjects without $\mathrm{BV}$. The vaginal community in BV+ group (Evenness $=0.592)$ was more even than in BV-group (Evenness=0.472) (Table 2) indicating that bacterial community in $\mathrm{BV}+$ group had greater species diversity.

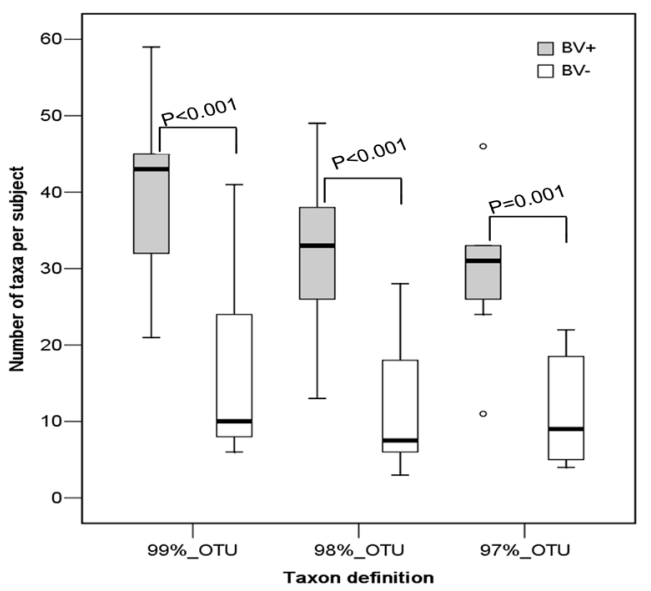

Figure 2: Numbers of taxa per subject using three different taxon definitions. Taxon definitions of $99 \%, 98 \%$, and $97 \%$ OTUs were assigned using the Mothur package.

The shaded boxes encompass the 25th to 75th percentiles of the data, the boldface lines indicate means, and the whiskers span the 5th to 95th percentiles. The asterisks indicate significantly $(P<0.001)$ differences in mean values for subjects with $\mathrm{BV}$ versus subjects without $\mathrm{BV}$, as determined by $\mathrm{t}$ tests.

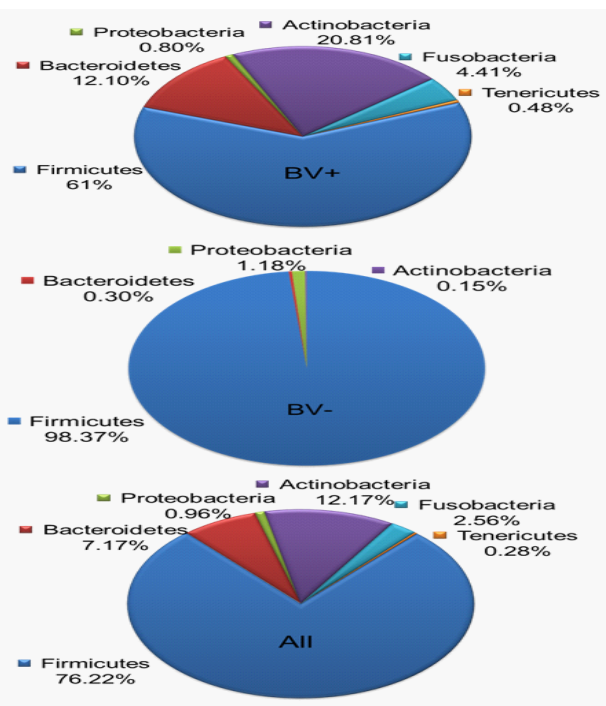

Figure 3: Pie chart representation for the overall abundance of phyla among the 20 libraries.

\section{Differential bacterial abundance found in $\mathrm{BV}+$ and $\mathrm{BV}$ - Groups}

A significant difference $(\mathrm{P}<0.001)$ was found between the subjects with BV and those without BV according to the mean number of taxa in each sample of Mean \pm SD with the $11.8 \pm 4.44$ in BV+ group and $3.9 \pm 3.35$ in BV- group.

The overall abundance was presented as pie charts in Figure 3. At phylum level, Firmicutes was the most abundant member in BV-group and Firmicutes and Actinobacteria was more abundant in BV+ group (Figure $3 \mathrm{~A}$ and B). Fusobacteria and Tenericutes were only found in samples from subjects with BV. There were differences in the relative proportions of major groups of bacteria for the taxonomic distribution of phylotypes. Taxonomic affiliations and relative proportions of sequences were summarized at the genus (Figure $4 \mathrm{~A}$ ) and phylum (Figure 4B) levels.

Proportions of Actinobacteria, and Bacteroidetes were 140 times and 40 times higher respectively in subjects with BV than those without BV. However Firmicutes in subjects with BV was only 0.62 times of that without BV. The dominant microflora is Lactobacillus iners in subjects without BV, which accounted for $83.73 \%$ of all bacterial communities (Figure 4A). In contrast, subjects with BV did not possess a single dominant taxon but rather harbored a diverse array of vaginal bacteria, many present at low relative abundance, including Gardnerella, Atopobium, Prevotella, Gemella, Aerococcus, L.iners, Anaerococcus, Parvimonas, Peptoniphilus, Megasphaera, Dialiste, and Sneathia. From the above, we can see that $\mathrm{BV}+$ group has a higher degree of microbial diversity.

The abundance of bacterial phylotypes from each subject was summarized in Table 3. Several species showed preferential occurrence in subjects of $\mathrm{BV}+$ group with $\mathrm{t}$-test $\mathrm{p}$ value $<0.1$ and this preference was analyzed by chi-test according to presence of species in the subject (Table 4). Most of these species were more prevalent in BV+ group.

\begin{tabular}{|c|c|c|c|c|c|c|c|}
\hline \multirow[t]{2}{*}{ Subjects } & \multirow{2}{*}{$\begin{array}{l}\text { No. of } \\
\text { Sequences }\end{array}$} & \multicolumn{6}{|l|}{ Phylum } \\
\hline & & $\begin{array}{l}\text { Fir- } \\
\text { micutes }\end{array}$ & $\begin{array}{l}\text { Bacte- } \\
\text { roidetes }\end{array}$ & $\begin{array}{l}\text { Proteobac- } \\
\text { teria }\end{array}$ & $\begin{array}{l}\text { Actino- } \\
\text { bacteria }\end{array}$ & $\begin{array}{l}\text { Fuso- } \\
\text { bacteria }\end{array}$ & $\begin{array}{l}\text { Teneri- } \\
\text { cutes }\end{array}$ \\
\hline \multicolumn{8}{|c|}{ BV+ Group } \\
\hline 124 & 165 & 38.55 & 3.01 & 0 & 51.81 & 6.02 & 0.6 \\
\hline 127 & 153 & 80.39 & 5.88 & 3.92 & 5.23 & 4.58 & 0 \\
\hline 130 & 121 & 5.79 & 5.79 & 0 & 28.1 & 21.49 & 0 \\
\hline 131 & 190 & 48.42 & 1.05 & 0 & 50 & 0 & 0.53 \\
\hline 133 & 181 & 66.3 & 10.5 & 0 & 15.47 & 7.73 & 0 \\
\hline 227 & 231 & 75.32 & 16.88 & 0 & 2.6 & 5.19 & 0 \\
\hline 228 & 229 & 94.76 & 1.75 & 0 & 3.49 & 0 & 0 \\
\hline 232 & 200 & 48 & 22 & 0.5 & 25 & 4.5 & 0 \\
\hline 245 & 224 & 78.13 & 0 & 3.57 & 15.18 & 0 & 3.13 \\
\hline 251 & 190 & 47.37 & 37.89 & 0 & 12.11 & 2.63 & 0 \\
\hline \multicolumn{8}{|c|}{ BV- Group } \\
\hline 113 & 118 & 100 & 0 & 0 & 0 & 0 & 0 \\
\hline 125 & 244 & 99.59 & 0.41 & 0 & 0 & 0 & 0 \\
\hline 136 & 199 & 99.5 & 0 & 0.5 & 0 & 0 & 0 \\
\hline 138 & 117 & 99.15 & 0 & 0.85 & 0 & 0 & 0 \\
\hline 146 & 153 & 89.54 & 0.65 & 8.5 & 1.31 & 0 & 0 \\
\hline 223 & 101 & 100 & 0 & 0 & 0 & 0 & 0 \\
\hline 229 & 106 & 100 & 0 & 0 & 0 & 0 & 0 \\
\hline 235 & 105 & 97.14 & 1.9 & 0.95 & 0 & 0 & 0 \\
\hline 237 & 105 & 100 & 0 & 0 & 0 & 0 & 0 \\
\hline 249 & 104 & 100 & 0 & 0 & 0 & 0 & 0 \\
\hline
\end{tabular}

Table 3: Abundance of bacterial phylotypes at Phylum level. 


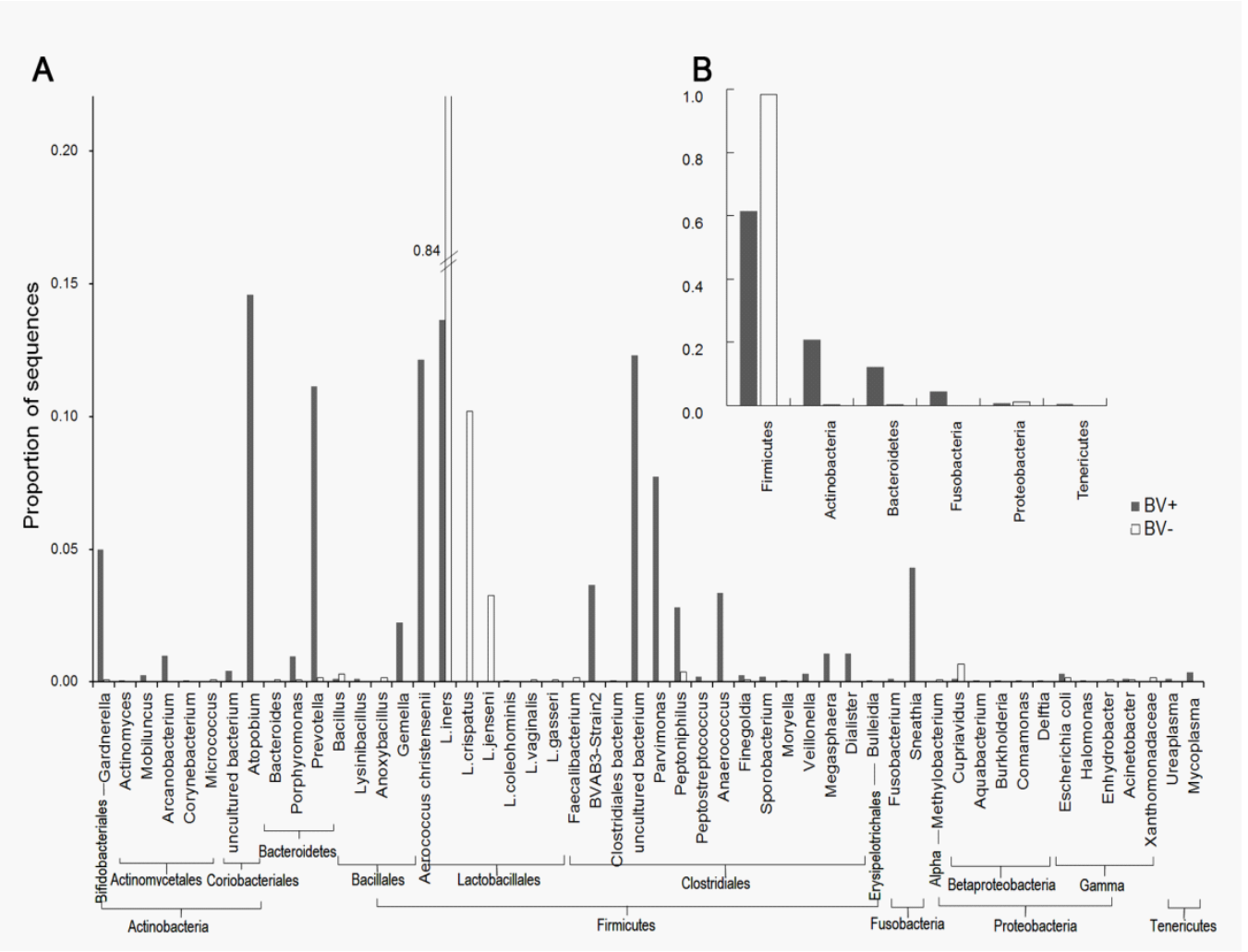

Figure 4: Taxonomic affiliations and relative proportions of sequences summarized at the genus (A) and phylum (B) levels. The taxa in panel A represent the closest matches from the RDP database. The y axes in both panels show the proportion of sequences from subjects with and without BV calculated separately. Note the break in the axis for Lactobacillus iners sequences from subjects without BV, where lactobacilli comprise $84 \%$ of the sequences.

Gardnerella vaginalis was one of the bacteria first found to be associated with BV [22]. In our research, Gardnerella vaginalis was found in 4 subjects in $\mathrm{BV}+$ group, with the occurrence of $10.3 \%, 17.37 \%, 0.87 \%$ and $15.18 \%$ in the subject $124,131,228$ and 245 respectively. In BVgroup, Gardnerella vaginalis was found in only one subject 146 with the occurrence of $0.65 \%$. In this study, the t-test $p$ value for abundance was only $<0.1$ and chi-test $p$ value for presence was $<0.5$. Although Gardnerella vaginalis was not more prevalent in BV+ group, its presence was more common in BV+ group (Figure 4).

There was a significant difference between $\mathrm{BV}+$ and $\mathrm{BV}$ - group in almost genera obtained from the vagina (Table 4). Not surprisingly, the Atopobium, Prevotella, Sneathia $(\mathrm{P}<0.01$ for chi-test, and $\mathrm{P}<0.05$ for t-test) had significantly strong association with BV. Among these predominant genera, Gemella, Anaerococcus, Parvimonas, Peptoniphilus, Dialiste, Megasphaera had weak associations with BV ( $<<0.05$ for only one test). Although they had been detected by previously studies, they were not identified as $\mathrm{BV}$-associated bacteria [5,23-26].

Lactobacillus bacteria were more abundant in BV-group, consisting of $97.6 \% \pm 9.6 \%$ and significantly higher than that in BV+ group, which was $12.2 \% \pm 26.6 \%(\mathrm{P}<0.001)$ (Figure 4$)$. Among the Lactobacillus species, L. iners, L. jensenii, L. crispatus, L. vaginalis and L. gasseri were found with overall occurrence of $83.73 \%, 3.25 \%, 10.21 \%, 0.07 \%$ and $0.07 \%$ in BV-group. Only L. iners and L. coleohominis were found with $13.63 \%$ and $0.05 \%$ in BV + group. L. iners was more prevalent in BVgroup with t-test $\mathrm{p}$ value of 0.001 and chi-test $\mathrm{p}$ value of 0.001 (Table
3). Chinese women are more likely to be colonized with $L$. iners than other Lactobacillus species in the vaginal ecosystem. This is consistent with Ravel, that among 96 Asian women, 41 had a vaginal microbiota dominated by $L$. iners [26]. The diversity of vaginal microbiota in healthy women from the Haerbing, Northern China, compared with the other area of China investigated [27,28]. L. vaginalis was present in subject 125 with $0.41 \%$ prevalence, and L. gasseri in subject 229 with $0.94 \%$.

Based on results of classification, four possible novel phylotype microorganisms were found. Two uncultured bacterium classified into the Ruminococcaceae family were apparent to be associate with BV, that uncultured bacterium AY958888 showed significant BVassociate $(\mathrm{P}<0.05$ for chi-test and $\mathrm{P}<0.1$ for $\mathrm{t}$-test $)$, another uncultured Acetivibrio bacterium $(\mathrm{P}<0.1$ for chi-test) which was indifined as BVAB3-Strain 2 by Fredricks [23].

Two additional unidentified bacteria were also found in this study, although not associated with BV. One classified into Coriobacteriaceae bacterium was presented in subject 130, 133 and 232 with prevalence of $1.65 \%, 0.55 \%$ and $2.5 \%$. The other classified into Clostridiales bacterium was presented in subject 131 with $0.52 \%$.

\section{Principal component analysis}

Principal Component Analysis (PCA) on the genera composition of microbes in each subject that represents an environment was performed using Canoco (Version 4.51) [29]. The clustering of the samples and the vectors contributing to the spread of the data points 
Citation: Liu Y, Hao W, Duan C, Tan J, Xu W, et al. (2012) Comparative Analysis of Vaginal Bacterial Diversity in Northern-Chinese Women Associated With or Without Bacterial Vaginosis. J Medical Microbiol Diagnosis S5:001. doi:10.4172/2161-0703.S5-001

Page 6 of 9

\begin{tabular}{|c|c|c|c|c|c|c|c|c|}
\hline \multirow[b]{3}{*}{ Genera } & \multirow[b]{3}{*}{ Genbank No. } & \multirow[b]{3}{*}{ prevalence (\%) } & \multicolumn{2}{|l|}{$\mathrm{BV}+$} & \multicolumn{2}{|l|}{ BV- } & \multirow{2}{*}{\multicolumn{2}{|c|}{$P$ value }} \\
\hline & & & \multirow[t]{2}{*}{ Mean (\%) } & \multirow[t]{2}{*}{ std } & \multirow[t]{2}{*}{ Mean (\%) } & \multirow[t]{2}{*}{ std } & & \\
\hline & & & & & & & T-test & chi-test \\
\hline Gardnerella & M58744.1 & 2.688 & 4.366 & 7.048 & 0.065 & 0.207 & 0.086 & 0.218 \\
\hline Actinomyces & HQ850579.1 & 0.031 & 0.065 & 0.207 & 0 & 0 & 0.343 & 0.739 \\
\hline Mobiluncus & AJ427624.2 & 0.154 & 0.249 & 0.486 & 0 & 0 & 0.14 & 0.28 \\
\hline Arcanobacteriu & HQ712123.1 & 0.494 & 0.884 & 2.795 & 0 & 0 & 0.343 & 0.739 \\
\hline Corynebacterium & AJ277970.1 & 0.031 & 0.053 & 0.166 & 0 & 0 & 0.343 & 0.739 \\
\hline Micrococcus & & 0.031 & 0 & 0 & 0.065 & 0.207 & 0.343 & 0.739 \\
\hline Uncultured & AY959023.1 & 0.247 & 0.471 & 0.887 & 0 & 0 & 0.128 & 0.28 \\
\hline Atopobium & AF325325.1 & 8.496 & 16.464 & 16.817 & 0 & 0 & 0.013 & 0 \\
\hline Bacteroides & AB510708.1 & 0.031 & 0 & 0 & 0.041 & 0.13 & 0.343 & 0.739 \\
\hline Porphyromonas & AB547668.1 & 0.587 & 1.017 & 1.771 & 0.065 & 0.207 & 0.125 & 0.143 \\
\hline Prevotella & AB547706.1 & 6.549 & 11.69 & 12.438 & 0.19 & 0.602 & 0.017 & 0 \\
\hline Lysinibacillus & JF309274.1 & 0.062 & 0.105 & 0.333 & 0 & 0 & 0.343 & 0.739 \\
\hline Anoxybacillus & AJ551330 & 0.062 & 0 & 0 & 0.131 & 0.413 & 0.343 & 0.739 \\
\hline Gemella & EU427463.1 & 1.297 & 2.493 & 4.311 & 0 & 0 & 0.101 & 0.002 \\
\hline Aerococcus & Y17318.1 & 7.074 & 10.249 & 29.372 & 0 & 0 & 0.298 & 0.481 \\
\hline L. iners & AY526083.1 & 42.91 & 12.159 & 26.198 & 81.476 & 29.976 & 0 & 0 \\
\hline L.crispatus & Y17362 & 4.263 & 0 & 0 & 12.276 & 30.624 & 0.237 & 0.023 \\
\hline Sporobacterium & EU483154.1 & 0.124 & 0.211 & 0.666 & 0 & 0 & 0.343 & 0.739 \\
\hline Moryella ; & AF527773.1 & 0.031 & 0.053 & 0.166 & 0 & 0 & 0.343 & 0.739 \\
\hline Anaerococcus & GQ422749.1 & 1.946 & 3.879 & 7.537 & 0 & 0 & 0.138 & 0.023 \\
\hline Finegoldia & AP008971.1 & 0.185 & 0.278 & 0.593 & 0.065 & 0.207 & 0.306 & 0.684 \\
\hline Parvimonas & GU470891.1 & 4.51 & 8.182 & 10.709 & 0 & 0 & 0.039 & 0.063 \\
\hline Peptoniphilus & AY244779.1 & 1.792 & 3.29 & 5 & 0.327 & 1.033 & 0.097 & 0.009 \\
\hline Peptostreptococcus & AY326462.1 & 0.124 & 0.223 & 0.382 & 0 & 0 & 0.098 & 0.28 \\
\hline Faecalibacterium & AF371731 & 0.062 & 0 & 0 & 0.082 & 0.259 & 0.343 & 0.739 \\
\hline Acetivibrio BVAB3 & GQ900632 & 2.132 & 3.508 & 6.141 & 0 & 0 & 0.104 & 0.28 \\
\hline Clostridiales bacterium & AF481208.1 & 0.031 & 0.053 & 0.166 & 0 & 0 & 0.343 & 0.739 \\
\hline uncultured bacterium & AY958888 & 7.167 & 10.973 & 18.509 & 0 & 0 & 0.094 & 0.063 \\
\hline Veillonella & AY244769.1 & 0.185 & 0.361 & 1.143 & 0 & 0 & 0.343 & 0.739 \\
\hline Megasphaera & DQ666098 & 0.618 & 1.044 & 1.811 & 0 & 0 & 0.102 & 0.143 \\
\hline Dialister & AB626633.1 & 0.618 & 1.056 & 1.45 & 0 & 0 & 0.047 & 0.739 \\
\hline Bulleidia & & 0.031 & 0.043 & 0.137 & 0 & 0 & 0.343 & 0.739 \\
\hline Fusobacterium & GQ301043.1 & 0.062 & 0.109 & 0.235 & 0 & 0 & 0.178 & 0.481 \\
\hline Sneathia & GQ179730.1 & 2.502 & 5.106 & 6.345 & 0 & 0 & 0.031 & 0.007 \\
\hline Methylobacteriu & GU294335.1 & 0.031 & 0 & 0 & 0.085 & 0.27 & 0.343 & 0.739 \\
\hline Cupriavidus & AB109753.1 & 0.34 & 0.131 & 0.413 & 0.588 & 1.86 & 0.458 & 0.971 \\
\hline Aquabacterium & AJ744886 & 0.031 & 0.05 & 0.158 & 0 & 0 & 0.343 & 0.739 \\
\hline Burkholderia & & 0.031 & 0.045 & 0.141 & 0 & 0 & 0.343 & 0.739 \\
\hline Comamonas & AB277849.1 & 0.031 & 0.065 & 0.207 & 0 & 0 & 0.343 & 0.739 \\
\hline Mycoplasma & & 0.216 & 0.313 & 0.988 & 0 & 0 & 0.343 & 0.739 \\
\hline Delftia & AB074256.1 & 0.031 & 0.065 & 0.207 & 0 & 0 & 0.343 & 0.739 \\
\hline Escherichia coli; & AF233451 & 0.247 & 0.268 & 0.847 & 0.131 & 0.413 & 0.651 & 0.971 \\
\hline Halomonas & & 0.031 & 0.045 & 0.141 & 0 & 0 & 0.343 & 0.739 \\
\hline Enhydrobacter & AJ550856 & 0.031 & 0 & 0 & 0.065 & 0.207 & 0.343 & 0.739 \\
\hline Acinetobacter & AJ275041.2 & 0.093 & 0.131 & 0.413 & 0.095 & 0.301 & 0.829 & 0.971 \\
\hline Xanthomonadaceae & GQ926873.1 & 0.062 & 0 & 0 & 0.116 & 0.246 & 0.172 & 0.481 \\
\hline Ureaplasma & AF073459.1 & 0.062 & 0.113 & 0.239 & 0 & 0 & 0.169 & 0.481 \\
\hline
\end{tabular}

alt is usually assumed that the prevalence distributions of parameters are Gaussian distribution. The parameters statistical test was performed by independent Student's $\mathrm{t}$ test first and

${ }^{\mathrm{b}}$ For those Equal variances not assumed, chi-square test was used to calculate the $\mathrm{P}$ value

The underscore characters for the $\mathrm{P}$ value $<0.05$, indicated that the prevalence of BV positive group is significantly differed from BV negative group.

Table 4: Genera of bacteria with high overall prevalence or with differential occurrence in BV+ vs BV- group.

were showed by the biplot in Figure 5. Lactobacillus, Anaerococcus, Prevotella and Sneathia contributed to the formation of a cluster, respectively. Parvimonas, Atopobium, Gemella, Gardnerella, and Dialister altogether contributed to the separation of a cluster. When the clusters from the PCA results were compared with the sialidase based BV test, nine out of ten subjects in BV+ group fall into the same cluster. The only exception was subject 245 with the dominant consist of $L$. iners. Although subject 245 had been treated for BV, the sialidase 


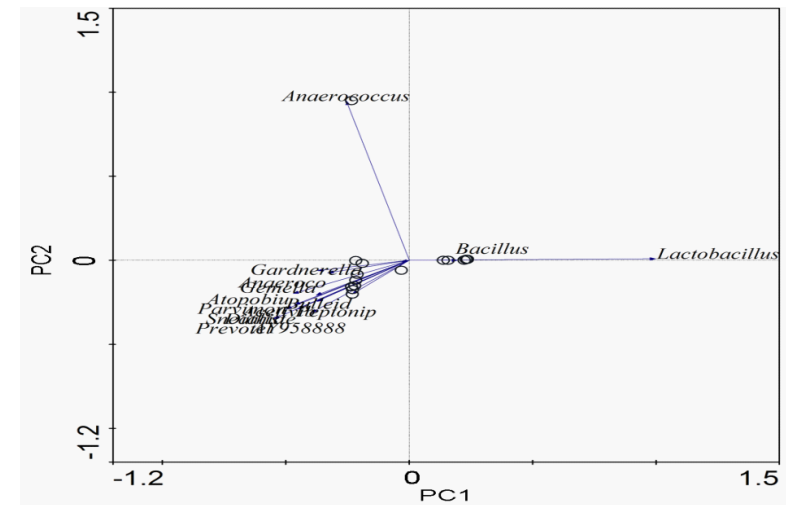

Figure 5: Biplot of principal component analysis results for the micobial centents at genus binning level.

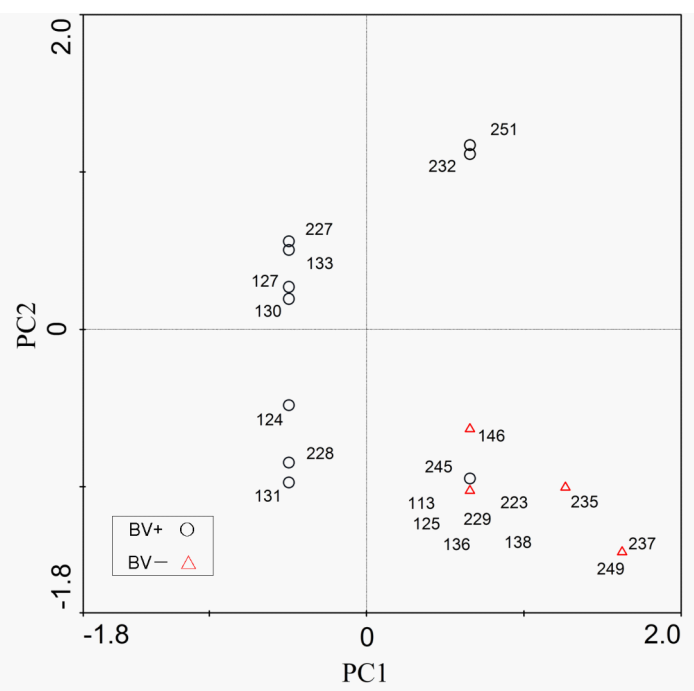

Figure 6: Clustering of subjects after principal component analysis.

test still showed positive result (Figure 6). This suggests that absence of $\mathrm{BV}$ associated bacteria from the survey of the vaginal microbiota is not associated with the immunological response to a recent BV episode.

\section{Discussion}

The human vaginal microbial ecosystem plays an important protective role in maintaining women's health. Acquisition of the diversity and composition of the human vaginal microbial ecosystem in health and diseased state can be valuable in understanding the etiology of the disease and to prevent and control them. Here, we analyzed the diversity of vaginal microbiota in BV positive and healthy women using full-length $16 \mathrm{~S}$ rDNA to better understand the diversity of healthy and diseased vaginal bacterial communities.

In subjects with clinically defined BV, the apparent change was the abundance of bacterial species and BV is associated with a dramatic increase in the taxonomic richness and diversity of the vaginal bacterial community. As to the bacterial cluster, there are 9 in BV subjects but only 1 in health subjects. Several bacteria such as Atopobium, Prevotella, Parvimonas, Peptoniphilus, Dialiste, and Sneathia were found to be highly associated with BV. We also found that the presence of BVassociated organisms can also be detected in women with normal flora..
In the previous reports, the dominating vaginal microbiota was Lactobacilli $[27,28,30-32]$.The species Lactobacillus iners, Lactobacillus crispatus, Lactobacillus jensenii, and Lactobacillus gasseri were found in the Asian Japanese, white and black women [30-33] while only the Lactobacillus iners, Lactobacillus crispatus were found in Eastern Chinese (Shanghai and Zhejiang) women [27,28]. In our study, the diversity of vaginal microbiota in healthy women from the Haerbing, Northern China was investigated. L. vaginalis was found in this investigation. Among the Lactobacillus species, L. iners, L. crispatus, L. jensenii, L. vaginalis, L. gasseri and L.coleohominis were found with overall occurrence of $42.91 \%, 4.26 \%, 1.35 \%, 0.03 \%, 0.03 \%$ and $0.03 \%$ respectively. $L$. iners and L.crispatus were more prevalent with t-test $\mathrm{p}$ value of $0.000,0.237$ and chi-test $\mathrm{p}$ value of $0.000,0.023$ (Table 4, Figure 4). Our results showed that the vaginal bacterial communities of healthy women are not always dominated by Lactobacillus species. The difference may be caused by the host genetic factors, cultural, behavioral and environmental differences.

In our research, we observed total of 213 taxa across all subjects with BV when taxon defined as $97 \%$ OTU definition, but richness estimates of the true number of taxa present ranged from 217 to 236 (95\% confidence interval), with an average estimate of 222 taxa (Table 2). Maybe the more samples could really reveal even greater richness and diversity in subjects with BV. While to subjects without BV, our samples were enough because we got 92 taxa with a $97 \%$ OTU definition with the total ranged from 93 to 107 (95\% confidence interval) (Table 2).

The variability in community membership and structure has important implications for understanding the etiology of BV and for developing diagnostic tools. Our data revealed that the vaginal bacterial communities found in subjects with and without BV are distinctly different. Notably, the structures of these vaginal bacterial communities have high inter subject variability within each clinical group. This is consistent with the reported inter subject variability in the vagina [23] and other areas of the human body [33, 34]. The possible reasons especially why the taxonomic composition of BVassociated bacteria is so different for each subject are: 1) differences in host immune response; 2) differences in geographic location; 3) expression of legends for bacterial attachment to epithelial cells; 4) the chemical and physical environments of the host; 5) intra- and inter specific microbial competition.

We identified several non-lactobacillus bacteria associated with BV, including Atopobium, Prevotella, Gemella, Anaerococcus, Parvimonnas and Peptoniphilus, and Dialister, Sneathia. At phylum lever, BVgroup consists of mostly Firmicutes while BV+ group also has higher abundance in Bacteroidetes and Actinobacteria. We found that species diversity was more richness in $\mathrm{BV}+$ group.

The preferential occurrence of several species in subjects of BV+ group was tested by t-test and analyzed strictly according to presence of absence of the species in the subject by chi-test. The results showed that most of these species were more prevalent in BV+ group. Gardnerella vaginalis was first found to be associated with BV. Gardnerella vaginalis was not more prevalent in $\mathrm{BV}+$ group, but its presence was more common in BV+ group. Notably, Among the Lactobacillus species, Only L. iners and L. coleohominis were found with overall occurrence of $12.16 \%$ and $0.05 \%$ for BV + group. At genus level, the subjects in $\mathrm{BV}$ - groups have fewer bacterial genera $(3.9 \pm 3.35)$ than $\mathrm{BV}+$ groups $(11.8 \pm 4.44)$. Several genera were found predominantly including Atopobium, Porphyromonas, Prevotella, Parvimonas, Peptoniphilus, Dialister, Aerococcus, Acetivibrio BVAB3, Leptotrichia and Sneathia 
Citation: Liu Y, Hao W, Duan C, Tan J, Xu W, et al. (2012) Comparative Analysis of Vaginal Bacterial Diversity in Northern-Chinese Women Associated With or Without Bacterial Vaginosis. J Medical Microbiol Diagnosis S5:001. doi:10.4172/2161-0703.S5-001

in BV+ group, this had been previously identified as BV-associated bacteria [23-26].

In previous reports about the microbial ecosystem in human gastrointestinal tract showed that the host immune system and the cell surface receptors may influence human-microbial symbioses and dictate adhesion of microorganisms [35,36]. McFall-Ngai [37] put forward the point of view that adaptive immunity plays a role in recognizing and managing the complex community composition of beneficial microorganisms in vertebrates. Based on the above, we proposed that similar selectivity may occur in vagina and the local vaginal immune system may play an important role in determining the composition of vaginal microbial communities.

\section{Conclusions}

The data presented here about the composition and richness of the vaginal microbial ecosystem in $\mathrm{BV}$ and health state will provide insight into the etiology of BV and the basis for the prevention and control of $\mathrm{BV}$ of microbial ecosystem in women.

\section{Acknowledgements}

This work was supported by the start grant from Guangdong province and Southern Medical University (to Shuhong Luo). We thank Yilong Luo, Yanghui Zheng and Yang Li for the sample collection. We thank Dr. Mengfei Ho and Dr. Brenda A, Wilson for critic reading of the manuscript.

\section{Authors' contributions}

$\mathrm{SL}$ and $\mathrm{ML}$ participated in the design of the study, the analysis of the data. $\mathrm{YL}$, $\mathrm{WH}, \mathrm{CH}, \mathrm{WX}, \mathrm{SZ}, \mathrm{JT}$ and $\mathrm{XL}$ participated in the sample collection, DNA extraction, PCR library construction, sequencing and interpretation of the data. SL, ML and YL wrote the manuscript. All authors read and approved the final manuscript.

\section{References}

1. Sobel JD (2000) Bacterial vaginosis. Annu Rev Med 51: 349-356.

2. Haggerty CL, Hillier SL, Bass DC, Ness RB; PID Evaluation and Clinical Health study investigators (2004) Bacterial vaginosis and anaerobic bacteria are associated with endometritis. Clin Infect Dis 39: 990-995.

3. Taha TE, Hoover DR, Dallabetta GA, Kumwenda NI, Mtimavalye LA, et al. (1998) Bacterial vaginosis and disturbances of vaginal flora: association with increased acquisition of HIV. AIDS 12: 1699-1706.

4. Verstraelen H, Verhelst R, Claeys G, De Backer E, Temmerman M, et al. (2009) Longitudinal analysis of the vaginal microflora in pregnancy suggests that $\mathrm{L}$. crispatus promotes the stability of the normal vaginal microflora and that $L$. gasseri and/or $\mathrm{L}$. iners are more conducive to the occurrence of abnormal vaginal microflora. BMC Microbiol 9: 116.

5. Hyman RW, Fukushima M, Diamond L, Kumm J, Giudice LC, et al. (2005) Microbes on the human vaginal epithelium. Proc Natl Acad Sci U S A 102: $7952-$ 7957.

6. Fredricks DN, Marrazzo JM (2005) Molecular methodology in determining vaginal flora in health and disease: its time has come. Curr Infect Dis Rep 7: 463-470.

7. Amsel R, Totten PA, Spiegel CA, Chen KC, Eschenbach D, et al. (1983) Nonspecific vaginitis. Diagnostic criteria and microbial and epidemiologic associations. Am J Med 74: 14-22.

8. Kim TK, Thomas SM, Ho M, Sharma S, Reich Cl, et al. (2009) Heterogeneity of vaginal microbial communities within individuals. J Clin Microbiol 47: 1181-1189.

9. Lane DJ (1991) 16S/23S rRNA sequencing. in Nucleic Acid Techniques in Bacterial Systematics, eds Stackebrandt E, Goodfellow M (Wiley, New York), , pp 115-175.

10. Edwards U, Rogall T, Blöcker H, Emde M, Böttger EC (1989) Isolation and direct complete nucleotide determination of entire genes. Characterization of a gene coding for $16 \mathrm{~S}$ ribosomal RNA. Nucleic Acids Res 17: 7843-7853.

11. Wilson KH, Blitchington RB, Greene RC (1990) Amplification of bacterial $16 \mathrm{~S}$ ribosomal DNA with polymerase chain reaction. J Clin Microbiol 28: 1942-1946.
12. Ewing B, Hillier L, Wendl MC, Green P (1998) Base-calling of automated sequencer traces using phred. I. Accuracy assessment. Genome Res 8: 175185

13. Ewing B, Green P (1998) Base-calling of automated sequencer traces using phred. II. Error probabilities. Genome Res 8: 186-194.

14. Chou $\mathrm{HH}$, Holmes $\mathrm{MH}$ (2001) DNA sequence quality trimming and vector removal. Bioinformatics 17: 1093-1104.

15. Cole JR, Wang Q, Cardenas E, Fish J, Chai B, et al. (2009) The Ribosomal Database Project: improved alignments and new tools for rRNA analysis. Nucleic Acids Res 37: D141-145.

16. Wang Q, Garrity GM, Tiedje JM, Cole JR (2007) Naive Bayesian classifier for rapid assignment of rRNA sequences into the new bacterial taxonomy. Appl Environ Microbiol 73: 5261-5267.

17. Field JG, Clarke KR, Warwick RM (1982) A Practical Strategy for Analyzing Multispecies Distribution Patterns. Mar Ecol Prog Ser 8: 37-52.

18. Bray JR, Curtis JT (1957) An Ordination of the Upland Forest Communities of Southern Wisconsin. Ecol Monog 27: 325-349.

19. Schloss PD, Westcott SL, Ryabin T, Hall JR, Hartmann M, et al. (2009) Introducing mothur: open-source, platform-independent, community-supported software for describing and comparing microbial communities. Appl Environ Microbiol 75: 7537-7541.

20. Roesch LF, Fulthorpe RR, Riva A, Casella G, Hadwin AK, et al. (2007) Pyrosequencing enumerates and contrasts soil microbial diversity. ISME J 1: 283-290.

21. Bunge J, M Fitzpatrick (1993) Estimating the number of species: A review. Journal of the American Statistical Association, 88, 364-373.

22. Gardner HL, Dukes CD (1955) Haemophilus vaginalis vaginitis: a newly defined specific infection previously classified non-specific vaginitis. Am J Obstet Gynecol 69: $962-976$.

23. Fredricks DN, Fiedler TL, Marrazzo JM (2005) Molecular identification of bacteria associated with bacterial vaginosis. N Engl J Med 353: 1899-1911.

24. Verhelst R, Verstraelen H, Claeys G, Verschraegen G, Delanghe J, et al (2004) Cloning of $16 \mathrm{~S}$ rRNA genes amplified from normal and disturbed vaginal microflora suggests a strong association between Atopobium vaginae, Gardnerella vaginalis and bacterial vaginosis. BMC Microbiol 4: 16.

25. Oakley BB, Fiedler TL, Marrazzo JM, Fredricks DN (2008) Diversity of human vaginal bacterial communities and associations with clinically defined bacterial vaginosis. Appl Environ Microbiol 74: 4898-4909.

26. Ravel J, Gajer P, Abdo Z, Schneider GM, Koenig SS, et al. (2011) Vagina microbiome of reproductive-age women. Proc Natl Acad Sci U S A 108 Suppl 1: $4680-4687$.

27. Shi Y, Chen L, Tong J, Xu C (2009) Preliminary characterization of vaginal microbiota in healthy Chinese women using cultivation-independent methods. $J$ Obstet Gynaecol Res 35: 525-532.

28. Ling Z, Kong J, Liu F, Zhu H, Chen X, et al. (2010) Molecular analysis of the diversity of vaginal microbiota associated with bacterial vaginosis. BMC Genomics 11: 488

29. Jan Leps, Petr Smilauer (2003) Using the Canoco for Windows 4.5 package Multivariate Analysis of Ecological Data using CANOCO edited by Cambridge University Press, ,43-58

30. Zhou X, Bent SJ, Schneider MG, Davis CC, Islam MR, et al. (2004) Characterization of vaginal microbial communities in adult healthy women using cultivation-independent methods. Microbiology 150: 2565-2573.

31. Zhou X, Brown CJ, Abdo Z, Davis CC, Hansmann MA, et al. (2007) Differences in the composition of vaginal microbial communities found in healthy Caucasian and black women. ISME J 1: 121-133.

32. Zhou X, Hansmann MA, Davis CC, Suzuki H, Brown CJ, et al. (2010) The vaginal bacterial communities of Japanese women resemble those of women in other racial groups. FEMS Immunol Med Microbiol 58: 169-181.

33. Eckburg PB, Bik EM, Bernstein CN, Purdom E, Dethlefsen L, et al. (2005) Diversity of the human intestinal microbial flora. Science 308: 1635-1638. 
Citation: Liu Y, Hao W, Duan C, Tan J, Xu W, et al. (2012) Comparative Analysis of Vaginal Bacterial Diversity in Northern-Chinese Women Associated With or Without Bacterial Vaginosis. J Medical Microbiol Diagnosis S5:001. doi:10.4172/2161-0703.S5-001

Page 9 of 9

34. Gao Z, Tseng CH, Pei Z, Blaser MJ (2007) Molecular analysis of human forearm superficial skin bacterial biota. Proc Natl Acad Sci U S A 104: 2927-2932.

35. Mazmanian SK, Liu CH, Tzianabos AO, Kasper DL (2005) An immunomodulatory molecule of symbiotic bacteria directs maturation of the host immune system. Cell 122: 107-118.
36. Dethlefsen L, McFall-Ngai M, Relman DA (2007) An ecological and evolutionary perspective on human-microbe mutualism and disease. Nature 449: 811-818.

37. McFall-Ngai M (2007) Adaptive immunity: care for the community. Nature 445: 153. 